\title{
José Campillo y las secuelas de la suspensión de 1739: un proyecto político para la Hacienda Real ${ }^{1}$
}

\author{
Anne Dubet ${ }^{2}$
}

Recibido: 8 de febrero de 2017 / Aceptado: 26 de abril de 2017

Resumen. En la suspensión de pagos de 1739 entraron en juego la relación de la monarquía con la gente de negocios junto a cuestiones políticas: ¿qué autoridad podía ejercer el Ministro de Hacienda sobre los responsables de Guerra o Marina? ¿qué límites se podían imponer al propio rey en el gasto? En el presente artículo se revisa una interpretación clásica según la cual ni el autor de la suspensión, Iturralde, ni su sucesor, Verdes Montenegro, resolvieron estas cuestiones, por estar personalmente comprometidos con la gente de negocios, debiéndose esperar a la llegada de Campillo para asistir al inicio del fin de los intereses privados sobre la Hacienda real. Para ello, examino el proyecto de Campillo, su estrategia política y su práctica en las relaciones con la gente de negocios y el control del gasto. Su estrategia no consistió en no apartar a los hombres de negocios, sino en imponerles nuevas reglas del juego compatibles con un proyecto centralizador.

Palabras clave: suspensión de pagos de 1739; ministro de Hacienda; Tesorería General; José Campillo; marqués de La Ensenada.

\section{[en] José Campillo and the Aftermath of the Failure of 1739: a Political Project for the Royal Treasury}

Abstract. The suspension of payments of 1739 raised the problem of the relation between the monarchy and businessmen, but also political questions: what authority could Secretary of the Treasury have on the Ministers of War or Sea-coast? What limits could be imposed on the proper king in the expense? I check a classic interpretation: according to this one, neither the author of the suspension, Iturralde, nor his successor, Verdes Montenegro, solved those questions, for being personally compromised with businessmen, and only Campillo initiated a virtuous way, expelling private interests from the Royal Finances. For it, I examine Campillo's project, his political strategy and his practice in the relations with businessmen and the control of the expense. I think that he didn't seek to expel businessmen, but to impose on them new rules compatible with a centralizing project.

Keywords: Suspension of Payments of 1739; Secretary of the Treasury; Treasury General; José Campillo; Marquis of La Ensenada.

\footnotetext{
$1 \quad$ Las investigaciones presentadas en este artículo fueron posibles gracias a una beca del Institut Universitaire de France (2011-2015) y a mi participación en el proyecto I+D Entre la venalidad y la corrupción en la Monarquía Hispánica durante el Antiguo Régimen. HAR 2014-55305.

2 Université Clermont Auvergne. Centre d'Histoire "Espaces et Cultures". Clermont-Ferrand, France E-mail: Anne.dubet@uca.fr
} 
Sumario. 1. Introducción. Lecturas de la suspensión de 1739. 2. Los retos de 1739-1740. 2.1. La suspensión de 1739: motivos, beneficiarios y víctimas. 2.2. El Ministro de Hacienda, los otros responsables y el rey: el conflicto de 1740. 3. El proyecto de Campillo en enero de 1741. 3.1. Mala administración, mala cuenta y razón. 3.2. Por un Ministro principal. 3.3. Alegato pro domo. 4. Las nuevas reglas del juego de Campillo. 4.1. La afirmación del Ministro. 4.2. Equilibrios entre casas de negocios. 4.3. Precios y premios. 5. Conclusión.

Cómo citar: Dubet, A. (2017): “José Campillo y las secuelas de la suspension de 1739: un proyecto politico para la Hacienda Real”, en Cuadernos de Historia Moderna 42.2, 629-652.

\section{Introducción. Lecturas de la suspensión de 1739}

En un número monográfico dedicado a las suspensiones de pagos de la monarquía española, no sorprende que un texto relativo al siglo XVIII aborde la suspensión de 21 de marzo de 1739. Sin embargo, no propondré aquí un estudio monográfico de esta suspensión, a la que dediqué otro trabajo ${ }^{3}$, sino que me interesaré por la forma como, dos años después, José Campillo resolvió los problemas políticos y financieros planteados por dicha suspensión. La decisión de suspender pagos adoptada en 1739 no es solamente el resultado mecánico de las dificultades de tesorería de la monarquía: si el nivel de los pagos suspendidos -100 millones de reales- es elevado, correspondiendo a algo menos de la mitad de las rentas ordinarias de un año en la España peninsular, se sitúa por debajo de la deuda corriente que, ya en 1739, es objeto de estimaciones anuales precisas en el seno de la Tesorería General ${ }^{4}$; asimismo, está lejos de alcanzar los 516 millones que, en 1754, se reconocerán como la deuda legada por Felipe V a su hijo ${ }^{5}$. La suspensión de 1739 fue objeto de un decreto, al contrario de las suspensiones anteriores, más discretas, lo que permite pensar que tras este decreto se esconde un proyecto político formulado por el entonces Secretario del Despacho de Hacienda, Juan Bautista de Iturralde. Este deseó modificar sustancialmente la relación entre la monarquía y sus acreedores y, para conseguirlo, se esforzó por redefinir las atribuciones del llamado Ministro de Hacienda ${ }^{6}$. Sus iniciativas provocaron tensiones en el seno del aparato de gobierno de la Monarquía que no se resolvieron con su forzosa dimisión ni por la actuación de su sucesor en el cargo, Fernando Verdes Montenegro. Campillo supo interpretar esta realidad a la hora de elaborar un proyecto político alternativo para el gobierno de la Hacienda real.

La relación entre la monarquía y los hombres de negocios se conoce menos para el siglo XVIII que para los siglos XVI y XVII. Contamos con buenos estudios sobre

3 Dubet, A.: "La suspensión de pagos de 1739: ¿una medida de "buen gobierno” de la Hacienda?", Espacio, Tiempo y Forma, 30, 2017, pp. 19-56.

4 Sobre este trabajo de estimación de la deuda: Dubet, A.: La Hacienda Real de la Nueva Planta (1713-1726), entre fraude y buen gobierno. El caso Verdes Montenegro y las reformas de la Hacienda, Fondo de Cultura Económica, Madrid, 2015, parte III.

5 Según las estimaciones hechas en la Junta de la Testamentaría, estudiadas por Torres SÁNCHEZ, R.: "Incertidumbre y arbitrariedad. La política de deuda pública de los Borbones en el siglo XVIII", Estudis, 34, 2008, pp. 263-282 (p. 271). Estos 516 millones corresponden a deudas formadas durante todo el reinado, en particular durante la Guerra de la Oreja de Jenkins, posterior por tanto a la suspensión de pagos de 1739. La cifra no refleja la deuda total, sino la reclamada ante la Junta de la Testamentaría hasta 1754.

6 Adopto la expresión en uso para designar al Secretario de Hacienda desde la década de los 1720. Sobre el proyecto político e institucional asociado a la expresión: Dubet, A.: "Entre razón y ciencia de la Hacienda: la conflictiva construcción de un modelo de buen gobierno de la Real Hacienda en España en la primera mitad del siglo XVIII", Espacio, Tiempo y Forma, 2015, n² 28, pp. 187-209. 
las formas indirectas de crédito a la monarquía, como fueron los arrendamientos de rentas reales y los asientos de provisión militar, así como de sus protagonistas, su inserción en la corte y la administración real. Por esta vía, se pueden reconstituir momentos de cambio en las relaciones entre monarquía y hombres de crédito, como la Guerra de Sucesión, la década de ejercicio del marqués de la Ensenada y los años de actividad del de Esquilache 7 . Una vía complementaria consiste en analizar los proyectos explícitos de los gobernantes, concernientes al espacio que se debe reservar a la gente de negocios en el gobierno de la Hacienda y a las formas de remuneración de sus servicios, así como la negociación suscitada al poner tales proyectos en obra. Esta línea de análisis aún no ha sido explorada en profundidad para el siglo XVIII, tal vez porque, hasta fechas recientes, ha prevalecido la idea de que el reformismo borbónico buscaba reducir el peso de los intereses privados en la Hacienda real. El examen de polémicas relativas a la mejor forma de recaudación fiscal, a las compañías de comercio, la venalidad de los oficios o la forma que debía adquirir la Tesorería Mayor obliga a renunciar a esta visión: no todos los reformadores borbónicos promueven la misma concepción del crédito y de las relaciones que el rey debería mantener con los hombres de negocios; además, las líneas de conflicto no se reducen a una oposición entre partidarios virtuosos de la administración directa y defensores corruptos de la indirecta ${ }^{8}$. Las aportaciones historiográficas de los últimos años precisan completarse para llegar a una visión global -no necesariamente lineal - de la política financiera de la monarquía. La suspensión de 1739 y sus secuelas ofrecen un interesante punto de observación. En efecto, los sucesivos responsables de la Hacienda real examinan varias opciones político-institucionales durante algunos meses, iniciándose en aquellos momentos una verdadera inflexión en las relaciones entre monarquía y hombres de negocios.

En un famoso artículo, Pablo Fernández Albaladejo interpreta la suspensión de marzo de 1739 como la culminación de un "viejo sistema" y el punto de partida de un profundo giro político9. Su argumentación es la siguiente. Hasta 1739-1740, la Hacienda real se administró como bienes privados, en asociación con los hombres de negocios; las soluciones contempladas para remediar las crecientes dificultades de financiación de la monarquía eran clásicos remedios escolásticos, como el proyecto de reducción del gasto ordinario elaborado por la Junta de Medios conducida por el

Véanse las síntesis siguientes y la bibliografía citada en ellas. DuBET, A. y LuIs, J. P. (dirs.) : Les financiers et la construction de l'Etat en France et en Espagne (milieu du XVIIe siècle-milieu du XIXe siècle), Rennes, PUR, 2011; Guerrero Elecalde, R. e Imízcoz Beunza, J. M.: "Negocios y clientelismo político. Los empresarios norteños en la economía de la monarquía borbónica" en OcAmpo SuÁRez ValdÉs, J. (ed.): Empresas y empresarios en el norte de España (siglo XVIII), Trea, Somonte-Cenero, 2012, pp. 331-362; TorRES SÁNCHEZ, R. (dir.): "El negocio de la guerra: la movilización de recursos militares y la construcción de la monarquía española (XVII y XVIII)", número monográfico de Studia historica. Historia moderna, nº 35, 2013, pp. 23-303; Bertrand, M., Dubet, A., Solbes Ferri, S. y Torres Sánchez, R. (dirs.): “Actores políticos y actores privados en el gobierno de la Hacienda hispánica, ss. XVIII-XIX”, Tiempos Modernos, n 30, 2015/1.

8 Delgado Barrado, J. M.: Aquiles y Teseos. Bosquejos del reformismo borbónico (1701-1759), Universidad de Granada, Universidad de Jaén, 2007. Torres SÁnchez, R.: El precio de la guerra. El Estado fiscal-militar de Carlos III (1779-1783), Madrid, Marcial Pons, 2013. Andúuar Castillo, F. y Felices de la Fuente, M. M. (dirs.): El poder del dinero. Ventas de cargos y honores en el Antiguo Régimen, Madrid, Biblioteca Nueva, 2011. Burgos Lejonagoitia, G.: Gobernar las Indias. Venalidad y méritos en la provisión de cargos americanos, 1701-1746, Universidad de Almería, 2015. DuBet, A.: "Entre dos modelos de gobierno de la hacienda militar. Las reformas de la Tesorería Mayor en España en 1721-1727” en GonzÁlez Enciso, A. (ed.): Un Estado militar. España, 1650-1820, Madrid, Actas, 2012, pp. 255-290.

9 Fernández Albaladejo, P.: "El decreto de suspensión de pagos de 1739 : análisis e implicaciones", Moneda y crédito, $\mathrm{n}^{\circ} 142,1977$, pp. 51-85. 
sucesor de José Patiño en la Secretaría de Hacienda, el marqués de Torrenueva, en 1737-1739. Las justificaciones de la suspensión dadas en el decreto de 21 de marzo de 1739 confirman, a su modo de ver, la apreciación posterior de Francisco Cabarrús en virtud de la cual la decisión protegió a los hombres de negocios más sólidos, a expensas de los titulares de las cartas de pago "más pequeñas", consolidando el "viejo sistema". Finalmente, la identidad del Secretario del Despacho de Hacienda que promovió la suspensión, Juan Bautista de Iturralde -uno de los hombres de negocios navarros más influyentes del momento- explica una decisión favorable a los intereses de su grupo social. Después de su caída (enero de 1740), era patente el poco éxito de la medida: siguió prevaleciendo el déficit a causa, en particular, de la guerra marítima. No obstante, el rey, como monarca absoluto, se negaba a imponer un límite de gasto a los responsables del departamento de Guerra ${ }^{10}$, una exigencia política que pesó decisivamente en la suerte del Ministro. Otro Secretario, José Campillo, inició en 1741 una política de reforma más radical del sistema financiero, caracterizada por su "dureza" hacia los hombres de negocios, el esfuerzo por centralizar la administración de la Hacienda, la preferencia por la administración directa de la recaudación fiscal y el intento de reducir la corrupción administrativa ${ }^{11}$. Otros estudios simplifican en extremo el razonamiento de Fernández Albaladejo sobre la inflexión de 1739-1741, dejando de lado la cuestión fundamental del absolutismo: explican que en 1741 Campillo continúa el proyecto de Hacienda pública en su día encarnado por José Patiño (idea que Fernández Albaladejo no comparte), después de un paréntesis de cuatro años en el que los sucesivos Secretarios de Hacienda, demasiado comprometidos con grandes casas de negocio, gestionaron el erario del rey como si fuera un bien privado ${ }^{12}$.

Coincido con la idea de que, entre 1739 y 1741, se asiste a una reorientación sustancial de la política financiera de la monarquía en sus territorios peninsulares. A mi modo de ver, sin embargo, la diferencia entre la política de Iturralde y la de Campillo no gira en torno a una supuesta oposición entre intereses privados y espacio público. Campillo construyó su propuesta como una alternativa tanto a la suspensión acometida por Iturralde como a la política ideada por su sucesor, Fernando Verdes Montenegro, en 1740, al objeto de restablecer el crédito real, desenvolviéndose el segundo en medio de una aguda controversia sobre las facultades respectivas del Ministro de Hacienda, los Secretarios del Despacho de Guerra y Marina, el Ministro de Guerra y el Almirante General de Marina ${ }^{13}$. Campillo, como intentaré mostrar, no

10 Se trataba de Sebastián de la Cuadra, titular de la Secretaría de Guerra, y del duque de Montemar, para quien se volvió a crear el empleo de Ministro de Guerra en marzo de 1737. GLESENER, T.: "Reformar el corporativismo militar: la acción política del duque de Montemar como ministro de guerra (1737-1741)", Cuadernos de Historia Moderna, $\mathrm{n}^{\circ} 41$ (2), 2016, pp. 313-335. Sobre los Secretarios: Escudero, J. A.: Los orígenes del Consejo de Ministros en España. La junta suprema de Estado, Madrid, Editorial Complutense, 2001, t. I, pp. 99-103. (1a ed. : 1979).

11 Fernández Albaladejo, op. cit. (nota 9).

12 Aquerreta, S.: Negocios y finanzas en el siglo XVIII: la familia Goyeneche, Pamplona, EUNSA, 2001. ZAFrA Oteyza, J.: Fiscalidad y Antiguo Régimen. Las rentas provinciales del reino de Granada (1746-1780), Junta de Andalucía/Instituto de Estudios Fiscales, 1991. Los Secretarios de Hacienda que sucedieron a Patiño fueron Mateo Pablo Díaz de Lavandero, marqués de Torrenueva (noviembre de 1736-marzo de 1739), Juan Bautista de Iturralde (marzo de 1739-enero de 1740), Fernando Verdes Montenegro (enero de 1740-febrero de 1741) y José Campillo (febrero de 1741-abril de 1743). Torrenueva e Iturralde eran importantes hombres de negocios. Verdes Montenegro era amigo de los hermanos Pandos.

13 Dubet, A.: "El Ministerio de Hacienda en peligro: conflictos políticos acerca del gobierno de la Hacienda en 1740", Studia Historica. Historia Moderna, vol. 39, 2017 (en prensa). 
buscó apartar a los hombres de negocios de la administración de la Hacienda real, sino imponerles, con la "dureza" señalada por Fernández Albaladejo, unas nuevas "reglas del juego" 14 que fuesen compatibles con un proyecto centralizador. Tal situación le llevó a alterar el reparto de competencias entre la Secretaría de Hacienda y los demás departamentos responsables. Al mismo tiempo -como sus predecesores- ideó una fórmula para poder llevar a cabo sus proyectos dentro de un marco cultural de corte absolutista, lo que es probablemente una de las claves de su éxito.

\section{Los retos de 1739-1740}

Como mostraron Ibáñez Molina y Delgado Barrado, Campillo desplegó una intensa actividad desde fines de 1740 para promover su candidatura a los empleos de Ministro de Hacienda ${ }^{15}$. Se benefició en aquel entonces del apoyo del marqués de Scotti, gobernador del infante Luis y hombre de confianza de la reina, y de Sebastián de la Cuadra, marqués de Villarías, Secretario del Despacho de Estado y de Guerra desde la muerte de Patiño ${ }^{16}$. No fue esta la primera tentativa de Campillo. En marzo de 1739, ofreció sus servicios entre líneas en una "Inspección de las seis Secretarías y calidad de sus Secretarios": su retrato del Secretario del Despacho de Estado ideal se parecía mucho a él -debía ser buen político antes que letrado, guiado por la razón y la prudencia-, mientras que el perfil del buen Secretario de Hacienda excluía a Iturralde en tanto un oficial de aquel nivel no debía ser rico ni pobre ${ }^{17}$. Esta candidatura no tuvo éxito, como tampoco la de enero de 1740, como relataría Jorge Astraudi, antiguo secretario de Campillo ${ }^{18}$. En enero de 1741, desde su intendencia de Zaragoza, Campillo adoptó una estrategia distinta a la de 1739. En la "Inspección" de 1739 había incidido en su saber de buen intendente, que conocía las implicaciones sociales y económicas de las formas de recaudación fiscal en las provincias; había evocado la necesidad de estudiar cómo fomentar el crecimiento demográfico y el comercio; también había señalado que un buen Ministro debía ser consciente de la necesidad de responder a la urgencia sin tratar a los súbditos con violencia. Cabe entender que estos argumentos generalistas no respondieron a las preocupaciones inmediatas del rey y la reina.

Empero, en 1741, solicitó sin tapujos el empleo de Ministro y la destitución de Fernando Verdes Montenegro aludiendo a una realidad que no dejaría bien parado a

14 Recojo la fórmula de Torres SÁnchez, R.: "Cuando las reglas del juego cambian. Mercados y privilegio en el abastecimiento del ejército español en el siglo XVIII", Revista de Historia Moderna, n 20, 2002, pp. 487-512.

15 El Secretario del Despacho de Hacienda suele llevar este título. Desde los años 1720, se le confió además la Superintendencia General de la Hacienda (con la excepción de Juan Bautista Orendain, de noviembre de 1724 a septiembre de 1726) y el gobierno del Consejo de Hacienda (excepto en los casos de Fernando Verdes Montenegro en 1724 y el marqués de Torrenueva). Cfr. DuBet, op. cit. (nota 6).

16 IbÁÑEz Molina, M.: "D. José del Campillo ante los problemas fiscales a principios de 1741", Cuadernos de Investigación Histórica, núm. 15, 1994, pp. 47-68.

17 "Inspección de las seis secretarías y calidad de sus Secretarios", Biblioteca Nacional (BNE), ms 2559. Reproduce el texto Escudero, op. cit. (nota 10), I, pp. 117-127. El diseño de las Secretarías propuesto en aquel entonces por Campillo fue una de las fuentes de inspiración del Marqués de la Ensenada.

18 Astraudi, J.: "Memoria curiosa y contestación del Comisario Ordenador Jorge Astraudi al amistoso encargo que se le hizo sobre el Ministerio de Josef Campillo, su elevación y fallecimiento en Madrid" (22/12/1776), en Rodríguez Villa, A.: Patiño y Campillo. Reseña histórico-biográfica de estos dos ministros de Felipe V, formada con documentos y papeles inéditos y desconocidos en su mayor parte, Madrid, Sucesores de Rivadeneyra, 1882, pp. 131-150. 
su antecesor en el cargo: todo iría mejor "si se mudase el Ministerio de Hacienda, del cual ya nadie ha de confiar, y le sucediese otro bien conceptuado con el público"19. El "otro", naturalmente, era él: Campillo prometía reducir los gastos si pasaran "por mi mano y dirección" 20 . Si bien su preocupación por las reformas fiscales iniciadas en 1740 era real, no pareció ser la razón principal de su oposición a Verdes Montenegro, como advirtiera Delgado Barrado ${ }^{21}$. Tampoco fue su argumento decisivo. Para justificar su pretensión, puso énfasis en los problemas más acuciantes del momento: "dejándole Su Majestad la libre administración de su real Hacienda, mantendría con ella sola el estado presente de la Guerra y Marina"22. Se trataba así de costear las operaciones de guerra terrestre y marítima en el Mediterráneo, remediando las dificultades de crédito causadas por el "corte general" de marzo de 1739. Para conseguirlo, resultaba "preciso unir en un sujeto las Secretarías de Guerra, Marina, Indias y Hacienda" ${ }^{23}$. Campillo se refería así a las dos dificultades a las que se enfrentaron sus predecesores inmediatos: la búsqueda de la mejor fórmula para el crédito al rey y la necesidad, para el Ministro de Hacienda, de imponer límites en el gasto a los responsables de Guerra y Marina.

\subsection{La suspensión de 1739: motivos, beneficiarios y víctimas}

Resultará de utilidad analizar el significado dado a la suspensión de pagos de 1739 por su promotor, Iturralde, para entender en qué medida Campillo se opuso después a su política ${ }^{24}$. El decreto de 21 de marzo suspendía el pago de unas cartas de pago provisionales del Tesorero General, el medio de pago ordinario en aquella época. En efecto, desde 1713, casi todos los pagos de la monarquía se hacían en nombre del Tesorero General: este emitía cartas de pago "sobre" varias rentas, dando estos efectos a los acreedores del rey para que pudieran pedir el pago efectivo a los depositarios, tesoreros o arrendadores de las rentas en las mesadas indicadas en los títulos. La fiabilidad del Tesorero General y, detrás de él, el crédito del rey, dependían por tanto de la puntualidad de los responsables de cada renta en el pago. Para proceder a la suspensión bastaba con anunciar que no se abonarían estas cartas de pago provisionales.

Como señala Fernández Albaladejo, la suspensión de 1739 no fue indiscriminada: el decreto, recogiendo argumentos dados por Iturralde al rey, se caracterizó por dar un trato diferenciado a los acreedores en función de la moralidad de sus operaciones:

1) A los "recaudadores" de rentas (los arrendadores de Rentas Provinciales) que habían dado mesadas anticipadas sin interés, no se les incluía en la suspensión. Asimismo, los Gremios de Madrid se vieron exentos porque el dinero que anticipaban procedía de "personas indiferentes que no han tenido negocios con mi real Hacienda".

\footnotetext{
19 "Discurso sobre la expedición de Italia", Zaragoza, 14/01/1741. Archivo Histórico Nacional (AHN), Estado (E), libro 3149.

20 Campillo a Villarías, 14/01/1741. AHN, E, libro 3149.

21 Delgado Barrado, op. cit. (nota 8), p. 48.

22 Carta a Scotti de 22/12/1741, resumida en la de Campillo a Villarías de Zaragoza, 14/01/1741. AHN, E, leg. 3149. IbÁÑEz Molina, op. cit. (nota 16) fue el primero en poner al día el conjunto de cartas en las que nos apoyamos.

23 Campillo a Villarías, 14/01/1741. AHN, E, libro 3149.

24 En este apartado 2.1. recojo las conclusiones de DuBET, op. cit. (nota 3).
} 
2) Los que habían hecho anticipaciones con dinero efectivo recibirían un interés del 3\% del principal, en lugar del $8 \%$ usual, desde la suspensión hasta el reembolso de su fondo.

3) A los acreedores que habían anticipado dinero con "créditos" o "libramientos o recibos de buena cuenta", es decir con efectos del Tesorero o de su cajero, se les reconocía el principal, pero no se les pagaría ningún interés. La disposición tenía tintes punitivos: se trataba de castigar a quien prestara al rey con el objeto de hacer "negocios con [su] real Hacienda". En particular, se sospechaba a los de la tercera categoría de haber adquirido cartas de pago "beneficiadas o socorridas en el comercio". Estos acreedores, para Iturralde, eran los principales responsables de la "mala distribución" de los caudales del rey por elevar el coste de los pagos de la monarquía. El término "beneficiar" se refería aquí al negocio que hacían cuando compraban a particulares efectos del Tesorero General, con fuertes descuentos, para solicitar después en la Tesorería el abono de los efectos en su valor nominal. Además de aprovecharse de la debilidad de pequeños acreedores, obligados por la miseria a malvenderles sus efectos, engañaban al rey al exigir que se les abonasen los efectos en un precio superior al que les habían costado. En 1739, estas prácticas llevaban un cuarto de siglo inquietando a los responsables de la Hacienda y los arbitristas. Se había intentado prevenirlas o limitarlas, reforzando el control del Tesorero General sobre sus efectos y el del Ministro de Hacienda sobre el Tesorero General.

Aunque Iturralde recogió un argumento bien conocido, su crítica no era solo un efecto retórico. La denuncia se dirigía a los individuos capaces de solicitar en la Tesorería General el pago de los efectos que "beneficiaron": según una opinión bastante extendida, se trataba de gente poderosa, esencialmente hombres de negocios que tenían tratos y cuentas con la monarquía, y eventualmente de cortesanos. Estamos lejos de los pequeños ahorristas que conmovieron a Cabarrús bastante tiempo después.

La suspensión, además, no atacaba a todos por igual. Tuvo un blanco preciso que identificamos gracias a una lista de los efectos suspendidos elaborada en 1740 y a las explicaciones dadas por Alejandro de Vega, oficial de la Secretaría de Hacienda de Iturralde y adalid de su obra. Los 100 millones de reales no abonados procedieron en efecto de cinco "anticipaciones" hechas a la caja de la Tesorería General por orden real (comunicada por Torrenueva) entre julio de 1738 y febrero de 1739, una parte significativa de las cuales se consiguieron gracias a Martín de Herce. Este personaje, vulgar "corredor" según Vega, se intituló "agente principal de la Tesorería General de la Guerra" desde principios de los años 1730. Para reunir el dinero de las anticipaciones, con la anuencia del Tesorero General y el Ministro de Hacienda, recibió efectos del Tesorero que colocaba en la plaza de Madrid, buscando individuos que se los comprasen con dinero efectivo o con otros "créditos" más antiguos distribuidos por el Tesorero -en este caso se cancelaban viejas deudas. La práctica parece haber empezado en tiempos de Patiño y, en 1736, la justificaban Torrenueva y el Tesorero Francisco Lobato, explicando que la confianza inspirada por Herce en Madrid permitió responder a urgencias. En la lista de los pagos suspendidos elaborada en 1740, las anticipaciones obtenidas gracias a la mediación de Herce representan las dos terceras partes de las revisadas por el contador; parte de ellas se hicieron en créditos. Al suspender el reembolso de estas anticipaciones, Iturralde, por tanto, pretendió oponerse a una forma de costear la Hacienda real que, como explicó Vega, exponía el crédito del Tesorero General, ya que su resorte era la compraventa de efectos de la Tesorería General. Vega atribuía esta "mala distribución" a la ignorancia culpable de Patiño. 
La suspensión también obedecía probablemente al deseo de Iturralde de proteger los intereses de su grupo de procedencia, la "constelación Goyeneche" 25 , frente a grupos o individuos que, durante los ministerios de Patiño y Torrenueva, fueron ocupando mayor espacio en los negocios del rey. Se trataba primero de hombres asociados a la recaudación de la renta del tabaco: Herce era Tesorero de la renta desde 1738 y parte de las anticipaciones que negoció debían reembolsarse con el producto de esta; además, entre los hombres cuyos efectos fueron suspendidos, figura Ventura de Pinedo, conde de Villanueva, Tesorero de la renta de Cruzada pero también Director de la renta del tabaco desde 1726; el mismo Torrenueva, predecesor de Iturralde y maestro de obras de la política denunciada, había sido también Director del Tabaco. El proceso abierto en la primavera de 1739 contra el Tesorero (Herce) y dos Directores de la renta (Pinedo y José Gómez de Terán) confirma la voluntad de Iturralde de debilitarlos. Otro prestamista importante, víctima de la suspensión, fue Juan Evangelista Giraldeli, arrendador de las Rentas Generales desde 1734 por Ambrosio María Andriani. Incluyamos aquí también, además de la elevada deuda suspendida a Giraldeli (casi 9 millones de reales), la decisión de Iturralde de volver a la administración directa de la renta y confiarla a dos nuevos directores, en diciembre de 1739, confirmando con ello su propósito de debilitar a la casa Giraldeli. Al mismo tiempo, Iturralde se propuso reformar la jurisdicción de las Rentas Generales y la del Tabaco, confiándolas a la sola junta del Tabaco. Por fin, como refirió Vega, estuvo en conflicto abierto con el jefe de Pinedo en la renta de la Cruzada, el cardenal Molina, Gobernador del Consejo de Castilla, reprochándole, entre otras cosas, su gestión poco limpia de la renta. Sería imprudente pensar que la política de Iturralde se limitó a la protección de sus paisanos. De hecho, no todos los nuevos directores de las rentas del Tabaco y Generales en 1739 fueron navarros ni todos los navarros escaparon de la suspensión. Me parece más probable que quisiera volver a la situación de inicios de la década de los 1720, que él contribuyera a crear: en aquel entonces, la "constelación Goyeneche" era el grupo dominante tanto en la recaudación de impuestos (en particular, las Rentas Provinciales) como en el gasto militar; el crédito de la Tesorería General dependía esencialmente de la colaboración con los recaudadores de Rentas Provinciales, los cuales, no se olvide, gozaban de la confianza del Ministro de Hacienda. La exención concedida a estos en el decreto de suspensión de 1739 se relaciona con esta dinámica, al menos desde mi punto de vista. Idealmente, el crédito a la monarquía debería volver a basarse en las cartas de pago "sobre" las Rentas Provinciales, remuneradas con derechos de conducción. Se dejaría de recurrir a las acrobáticas maniobras de Herce, que Iturralde y Vega atribuían a la poca vigilancia del Ministro. Iturralde, por tanto, quiso consolidar las facultades del Ministro de Hacienda, devolviéndole el empleo de Gobernador del Consejo de Hacienda e iniciando una reforma tendente a reducir el peso de los letrados, lo que le valió la enemistad de Molina.

\subsection{El Ministro de Hacienda, los otros responsables y el rey: el conflicto de 1740}

En estas condiciones, parece legítimo pensar que la caída de Iturralde no se debió solo a la ineficacia financiera de la suspensión, y por tanto, a su supuesta incapacidad

Dedieu, J. P.:"Les groupes financiers et industriels au service du roi - Espagne. Fin XVIIe - début XVIIIe siècle", en Dubet y Luis, op. cit. (nota 7), cap. 5 
como ministro ${ }^{26}$. La caída de Iturralde también vino propiciada por la oposición de los grupos afectados por su política. Parece corroborar esta lectura el que uno de sus principales enemigos, el cardenal Molina, condujese la política financiera de la monarquía en 1740, presidiendo la Junta de Hacienda creada en enero de 1740 para asesorar al nuevo Ministro de Hacienda, Verdes Montenegro, su "hechura" según $\mathrm{Vega}^{27}$. Parte de las decisiones de esta junta invalidaban las del año anterior ${ }^{28}$. Así, se anularon las reformas del Consejo de Hacienda y de la jurisdicción de las Rentas Generales y del Tabaco. Se depuso a los flamantes Directores de Rentas Generales para dar la Superintendencia de la renta a Verdes Montenegro en calidad de Superintendente General de Hacienda. Y, por encima de todo, a 6 de abril el rey dio a conocer su opinión en contra de la suspensión, invitando a los interesados en ella a proponer medios para "extinguir" (reembolsar) sus cartas de pago sin faltar a las obligaciones del Estado. Finalmente, la Junta de Hacienda intentó reanudar el diálogo con algunos de los hombres de negocios más afectados: en la primavera, Pinedo concedió otra anticipación; durante el verano, Molina condujo la negociación con varios individuos para obtener anticipaciones sobre las rentas de $1741 \mathrm{y}$, para arrancarles mejores ofertas, recurrió a Herce, oportunamente liberado de su cárcel. El argumento utilizado entonces para justificar esta solución se oponía exactamente a la prosa de Iturralde. En efecto, se retrató a Herce como un experimentado conocedor de la plaza de Madrid, capaz, gracias a su prudencia y su discreción, de obtener anticipaciones de pequeños detentadores de capitales: estos últimos, lejos de buscar el lucro, usarían los fondos de sus testamentarías y sus fundaciones para servir al rey o invertirían en acciones caritativas las ganancias obtenidas en las anticipaciones. A pesar de estos esfuerzos, pocos acreedores se dejaron seducir, circunstancia que aprovecharía Campillo para promover su candidatura.

En cualquier caso, conviene no exagerar la oposición entre la política de Iturralde y la de Verdes Montenegro. Así, el segundo estaba determinado a mantener la administración directa de las Rentas Generales, a pesar de la presión de Giraldeli y de la opinión contraria de parte de la Junta de Hacienda, que estuvo a punto de imponer su criterio. Además, los dos ministros se enfrentaron a una misma dificultad política, que se hizo más contundente en 1740 en razón de la guerra: la resistencia de los responsables de los departamentos más gastadores (Guerra, Marina, Casas Reales) a someterse a una regla común para definir el gasto de la monarquía. Detrás de ellos, estaba el propio rey, quien, como apuntó Fernández Albaladejo, imponía su criterio de monarca absoluto. Este conflicto llevó a poner en tela de juicio el edificio institucional construido en las dos décadas posteriores a la Guerra de Sucesión. A fines de 1740, el duque de Montemar, Ministro de Guerra desde marzo de 1737, y los responsables del Almirantazgo de Marina creado el mismo mes $^{29}$, asesorados por

26 J. Caro Baroja criticó con razón el argumento de la incapacidad de los hombres de negocios para el gobierno de la Hacienda real, recordando que, según Sempere y Guarinos, Iturralde fue un excelente gestor de la Renta de Población que comprara al rey en 1725. CARo Baroja, J.: La hora navarra del XVIII (personas, familias, negocios e ideas), Pamplona, Comunidad Foral de Navarra, 1985, pp. 229-230 (1 ${ }^{\text {a }}$ ed. 1969).

27 Andújar Castillo, F.: "La hacienda real en tiempos de crisis: 1739-1741" en Cortés Peña, A. L., LópezGuadalupe Muñoz, M. L. y Sánchez-Montes González, F. (eds.): Estudios en homenaje al profesor José Szmolka Clares, Granada, Universidad de Granada, 2005, pp. 537-546. Delgado Barrado, op. cit. (nota 8).

28 En este apartado me baso en DuBET, op. cit. (nota 13).

29 Sobre esta doble creación y su significado: Pérez Fernández Turégano, C.: "El Almirantazgo del Infante don Felipe (1737-1748). Conflictos competenciales con la Secretaría de Estado y del Despacho de Marina", Anuario de Historia del Derecho Español, 74, 2004, pp. 409-476; GLESENER, op. cit. (nota 10). 
el secretario del mismo, el marqués de La Ensenada, obtuvieron sendas consignaciones anuales particulares pagaderas en la Tesorería General, por órdenes que no fueron comunicadas por Verdes Montenegro sino, probablemente, por el Secretario de Estado Villarías. La disposición hacía caso omiso de la planta de la Tesorería General que, desde Patiño, preveía que el único responsable de la distribución de los caudales fuera el Ministro de Hacienda. Además, ponía fin a lo que el Tesorero José Prado Güemes -elegido por Iturralde y mantenido por Verdes Montenegro- describió como la "unidad del manejo" de los caudales en la Tesorería: cada mes el Tesorero y el Ministro examinaban los fondos disponibles para asignarlos a los gastos más urgentes; sería imposible hacerlo si Guerra y Marina recibían la mayor parte de su consignación al principio del año. El conflicto acabó paralizando a la Junta de Hacienda, concebida inicialmente como un foro de negociación entre el Ministro de Hacienda y los responsables de los departamentos más gastadores, en particular el Ministro de Guerra y los tenientes generales de Marina. El remedio político imaginado por Verdes Montenegro en enero de 1741 acabó en un rotundo fracaso: propuso que la Junta de Hacienda asumiera la distribución de los caudales. En este punto intervino Campillo.

\section{El proyecto de Campillo en enero de 1741}

Planteada la situación anterior al acceso de Campillo a la Secretaría del Despacho de Hacienda, examinemos la política adoptada por este a partir de 1741. La primera etapa es una campaña de autopromoción iniciada desde su intendencia en Zaragoza. Los argumentos de que Campillo se vale en ella demuestran que, en los meses anteriores, examinó con atención los retos políticos y financieros a que se enfrentaron sus dos predecesores, intentando construir una respuesta diferente, para distinguirse y para sortear los escollos que perdieron a Iturralde y Verdes Montenegro. Así, en las cartas y memoriales que escribe en enero de 1741, deja entender que conoce el conflicto que enfrenta al Ministro de Hacienda y los responsables de Marina y Guerra, describiéndose a sí mismo como la mejor solución ante la crisis política. De este modo, no solo demuestra su superioridad sobre Verdes Montenegro, como notó Ibáñez Molina ${ }^{30}$, sino también sobre Montemar y Ensenada. A la carta escrita a Villarías a 14 de enero, añade tres ensayos, sobre el comercio con América, las campañas de Italia y el detalle de los gastos y rentas de la monarquía. A 7 de febrero, invitado ya a presentarse en Madrid, presenta un resumen de toda su propuesta, radicalizando algunas de sus ofertas ${ }^{31}$. En estos textos no se muestra tímido a la hora de presentarse como un perfecto oficial con capacidad para poner en marcha un programa que resuelva la situación en la que se encuentra la monarquía. Para ello, hace alarde de talentos variados como expresión misma de la imagen del perfecto ministro.

\subsection{Mala administración, mala cuenta y razón}

Ocupan el primer plano las competencias del Ministro de Hacienda. El punto de partida es un estado de fondos y cargas anuales preparado bajo la dirección de Verdes

IBÁÑEZ MolinA, op. cit. (nota 16).

31 Cartas conservadas en AHN, E, libro 3149. 
Montenegro en la Tesorería General en marzo de 1740, que Campillo pudo recuperar a pesar de su carácter reservado. Su lectura del documento busca demostrar que conoce el estado de las principales rentas de la corona en España, basando en ello su crítica a la mala praxis administrativa que viene dándose desde hace unos veinte años. Campillo entra en detalles para demostrar la amplitud de sus conocimientos, citando los nombres de los que considera culpables últimos de esta situación. Así, en las Rentas Generales, los arrendadores estafaron a la Real Hacienda al pagar un precio muy inferior al producto real, por lo que condena el nuevo proyecto de arrendamiento ("se ha admitido malamente pliego"); pero la administración directa tampoco fue fructífera dados los fraudes cometidos antes de 1734 y en 1740. En las Rentas Provinciales, siempre según su opinión, los arrendadores pagan precios indecentes al rey, en particular Pontejos, recaudador de Sevilla, por lo que Campillo propone colocar estas rentas bajo su propia "administración general".

En la renta del tabaco, el fraude florece en los estancos y las administraciones de las provincias. Campillo asimismo condena la excesiva codicia de los arrendadores de la renta de las lanas: "la renta de lanas está bárbaramente arrendada, sobre quinquenios de tiempos en que estuvo abandonada", como lo demuestra el que el arrendador, Miguel de Arizcun, propuso de motu proprio elevar el precio: pasó de 2,5 a 5,5 millones, cuando la renta vale 11. En este caso, la negligencia o la complicidad de los gobernantes es patente ya que no se recibió ni admitió puja alguna sobre esta renta. El comentario revela que Campillo tiene acceso a información privilegiada: en varias ocasiones, compara el valor presente de las rentas con sus valores pasados. Además de conocer la administración de las rentas, demuestra su dominio de la confección del estado de cargas y fondos. Así, advierte casos de duplicación, evidenciando la responsabilidad de los oficiales que prepararon el documento o sus jefes: "el presupuesto se hizo a ojo y solo por encarecer la cura". En febrero de 1741, remacha el argumento: él es capaz de justificar todas sus propuestas con "instrumentos de las tesorerías" (sin duda las de ejércitos, agencias de la Tesorería General, que conoce bien en su calidad de Intendente). Además, el análisis del estado de la hacienda le permite hacer ostentación de otras virtudes que se atribuye. Comenta en efecto los gastos de Guerra, Marina, Ministerio y Casas Reales, partida por partida, enfatizando su conocimiento de la organización material de la guerra y de la marina en particular, así como del trabajo en las intendencias. En cada caso, compara el coste real con el gasto previsto, refiriendo algunas de las artimañas con que los empleados exageran el gasto. En el ensayo sobre Italia, hace alarde de su conocimiento del terreno, las exigencias materiales del traslado del ejército y las formas de guerra más previsibles. El buen Ministro es también el que tranquiliza a los hombres de negocios para poderlos solicitar en casos de urgencia. Lo expone en las mismas páginas, dando la lista de los contactos y amigos que pueden facilitar la provisión militar en Italia.

\subsection{Por un Ministro principal}

El ministro ideal que describe Campillo, por tanto, debe mostrar un notable conocimiento de los ramos de hacienda, pero también de guerra y marina. De forma implícita, Campillo trata de demostrar que si Verdes Montenegro conocía la cuenta y razón, en realidad sabía poco de los otros capítulos. Campillo también busca justificar su proyecto institucional: en su opinión, la solución a las dificultades presentes 
es la vuelta al modelo de Patiño, citado en la carta ${ }^{32}$. Estas soluciones se manifestarán en tres ámbitos:

1) Por una parte, conviene reforzar la vía reservada, comenzando con el área de guerra. Así, los negocios que ha tratado el Consejo de Guerra desde 1721 cuando "el señor marqués de Castelar le resucitó (...) no valen lo que cuesta”. Se le podría suprimir, remitiendo la mayor parte de los negocios a la vía reservada y lo contencioso a "una de las Salas de gobierno del Consejo de Castilla, que tampoco tienen mucho que hacer". La ausencia de mención del empleo de Ministro de Guerra creado para Montemar en 1737 probablemente se debe a la poca estima que siente el intendente de Aragón hacia el duque. En los negocios de Indias, ya casi todo se trata por vía reservada, por lo que podrían jubilarse los consejeros de capa y espada. Por otro lado, "en el de Hacienda sucede lo mismo, escandalizando su número y calidad". Campillo repara aquí en la falta de inteligencia en materia de Hacienda de los consejeros. Recurre para solventar esta situación a la vía reservada como el espacio en que se habrán de tratar los negocios sin perder tiempo, con trabajo (en contraste con la ociosidad de los Consejos) y con inteligencia en las materias tratadas. De paso, aprovecha la oportunidad para mencionar las juntas: "debieran suprimir todas las juntas y reintegrar a los tribunales a que toquen en los negocios que en ellas se tratan y se extrajeron por fines particulares de los Gobernadores o Presidentes, con poca utilidad pública". El ataque, a mi entender, se podría dirigir a la junta de baldíos, presidida por el cardenal Molina, o a la propia Junta de Hacienda ${ }^{33}$.

2) De forma implícita, los méritos descritos anteriormente implican que el Ministro de Hacienda debe ser Gobernador del Consejo, para retomar el control sobre el Consejo y perseguir el fraude. También debe ocupar los empleos de Superintendente, para asegurar la buena recaudación de las rentas, y de Secretario, reforzando así la vía reservada, una asociación ya experimentada por el marqués de Campoflorido (1721-1724), por Patiño, por Iturralde y por el mismo Verdes Montenegro en su ejercicio de 1740 .

3) Por fin, como presupone la exposición de talentos necesarios, para que el Ministro de Hacienda lleve su tarea a cabo, "será preciso unir en un sujeto las Secretarías de Guerra, Marina, Indias y Hacienda". Campillo atribuye a Patiño esta idea de fusión de áreas de gobierno.

Esta concentración de facultades en manos de un solo hombre se debe traducir, lógicamente, en la reducción de las cajas particulares. Después de proponer suprimir las juntas inútiles, Campillo invita en efecto a

“extinguir también todas las pagadurías o tesorerías y contadurías particulares que hay en Madrid y son superfluas y establecidas solo porque acomodaban a los que las tienen, respecto de la buena armonía de la Tesorería General, en que sin confusión se llevaría la cuenta y razón más exactamente que en otra oficina alguna

32 Campillo recuerda que Patiño le recomendó a menudo la unión entre las Secretarías del Despacho de Indias, Marina, Hacienda y Guerra. Carta a Villarías, 14/01/1741. AHN, E, leg. 3149. Delgado Barrado, op. cit. (nota 8), p. 49.

33 Una confirmación de ello viene dada a posteriori por una crítica anónima de la política de Campillo, redactada entre el decreto sobre los juros de 07/07/1742 y la muerte del Ministro. El autor anónimo, quien sin duda tuvo entre manos la prosa de enero de 1741 que estamos comentando ahora, defiende la política de los tres predecesores de Campillo, en particular valorando los buenos resultados de la junta de baldíos y las innovaciones fiscales de la Junta de Hacienda, que Campillo criticó antes de ser Ministro, pero conservó. BNE, ms 12.641, fols. 192-217. 
y los caudales se tendrán por cuenta aparte o se mezclarán según el agrado de $\mathrm{Su}$ Majestad." ${ }^{34}$

Además de ahorrar gastos de contadores, pagadores y tesoreros inútiles en Madrid, se trata por tanto de facilitar el control contable. Dicho sea de paso, el comentario revela que Campillo conoce la reclamación de Prado Güemes y Verdes Montenegro sobre la "unidad del manejo" en la Tesorería General.

\subsection{Alegato pro domo}

En suma, Campillo se presenta en sus escritos como el único sujeto capaz de responder a lo que reclaman la junta de Hacienda y el monarca, apoyando su política en una reducción del gasto y el crecimiento de las rentas. Cuantifica su propuesta: podría elevar las rentas en 8 millones de escudos, y reducir los gastos en 7 millones (8 si él es Ministro) o, como corrige en febrero -ya con buenas expectativas de suceder a Verdes Montenegro-, 6,6 millones. La Hacienda pasaría así de ser deficitaria a excedentaria en 3 millones ${ }^{35}$. La solución se opone al gobierno colegial a que Verdes Montenegro acabó resignándose por incapacidad política: se trata ahora de volver a crear un Ministro de Hacienda único, cuya inteligencia en las materias de Hacienda, Marina y Guerra le protegerá contra los engaños de los hombres de negocios y de sus propios agentes. Poner en obra este programa implica liquidar parte de lo realizado por sus predecesores y cortar cabezas, si se me permite la expresión. Así, la administración directa de Rentas Generales apenas es más fiable que los arrendadores, por lo que propone recurrir a la administración durante dos años antes de elevar el precio del arrendamiento; ciertos hombres de negocios son claramente abusivos (Giraldeli, a quien no se nombra, Pontejos, Arizcun ...), lo que anuncia una renegociación de sus contratos; la "administración general" de las Rentas Provinciales no necesariamente significa su administración directa en cada provincia, aunque sí lleva implícita la creación de una dirección única desde la corte, al estilo de la del tabaco o la de Rentas Generales. En el gobierno, aunque designa a Verdes Montenegro como al principal culpable de la situación creada, ya advertimos que no dejó pasar la oportunidad de acusar a Molina. La demostración del gasto excesivo de Guerra y Marina incrimina a los demás responsables, Montemar, los tenientes generales de Marina, miembros de la Junta de Hacienda, y Ensenada. Campillo critica en este punto al primero en el ensayo sobre la guerra en Italia, que enuncia las consideraciones que el Ministro de Guerra tal vez omitió. Según el antiguo protegido de Campillo, Astraudi, la enemistad nació en Italia cuando Campillo era intendente del ejército (17331737) y Montemar era comandante en jefe del mismo ${ }^{36}$. En cuanto a los responsables de Marina, dan órdenes "a bulto", abusando del nombre del infante Almirante. Del Secretario de la junta del Almirantazgo, Ensenada, Campillo "cono[ce] a fondo su genio y que por habérsele inmaturamente pasado de grado en grado no ha podido formarse". Por eso es verosímil -según Campillo - el rumor de que "ha confundido la Marina". Además, los tenientes generales han expuesto a Campillo los manejos

34 Campillo a Villarías, 14/01/1741. AHN, E, leg. 3149.

35 Campillo a Villarías, 14/01/1741 y 07/02/1741. AHN, E, leg. 3149. La valoración de Campillo sobre el poco talento de Ensenada en cuestiones de Hacienda será desmentida por la política de este. Cfr. Dubet, "El marqués de Ensenada y el crédito del rey de España”, en prensa.

36 Astraudi, op. cit. (nota 18), pp. 131-132. 
abusivos de la junta (del Almirantazgo). Para sustituirlos, lo único que necesita un buen Ministro, además de la reunión de todos los empleos de dirección de la Hacienda y de las tres Secretarías, es el ingrediente político clave, la confianza de los reyes: "y la fe con que Sus Majestades le eligiesen y entregasen su confianza conciliaría el aplauso y fe universal y le pondría en disposición de que los hombres de comercio le sacasen de cualquier aprieto en que le viesen"37.

Astraudi se percata años después de la habilidad de una propuesta destinada a satisfacer ante todo a la reina, seducida, en su opinión, por la promesa de mandar 40.000 (según las cartas de Campillo) o 50.000 (según Astraudi) hombres a Italia. La referencia de Campillo al apoyo de los reyes en plural muestra que sabe que este apoyo es determinante, tal vez aleccionado por Patiño o por la caída de Verdes Montenegro. Sin duda la confianza de Isabel Farnesio es decisiva en su éxito, aunque puede que busque otros apoyos dando a conocer sus argumentos en la corte ${ }^{38}$. Pero su habilidad también reside en la precaución que toma para tranquilizar a los reyes sobre su margen de maniobra de monarcas absolutos. En efecto, aunque pretende restablecer la Tesorería General como única vía para la distribución de los caudales de la monarquía, precisa que "los caudales se tendrán por cuenta aparte o se mezclarán según el agrado de Su Majestad", como ya notamos. La mención del interés de Felipe $\mathrm{V}$ por esta cuestión técnica solo tiene sentido si nos referimos al último punto de conflicto entre Verdes Montenegro y los responsables de Guerra y Marina. Campillo comparte con Verdes Montenegro la idea de que la distribución de los caudales del rey debe obedecer a una unidad de criterio. Sin embargo, las modalidades son distintas. Para Verdes Montenegro, esta unidad de criterio debía traducirse en términos administrativos en lo que describía como la "unidad del manejo" de los caudales del rey en la Tesorería General, suprimiéndose las consignaciones particulares en el seno de esta. Campillo, al contrario, parece dispuesto a transigir con la voluntad de Felipe V de conferir un elevado grado de autonomía al Almirante General de Marina, tolerando una "cuenta aparte" en el seno de la Tesorería, porque piensa que la unidad de criterio no reside tanto en la gestión de la Tesorería como, en un nivel superior, en la dirección del Ministro de Hacienda.

\section{Las nuevas reglas del juego de Campillo}

Es famoso el juicio de Cabarrús sobre la política de Campillo:

"Fomentar los arriendos de las rentas como medios más prontos sin detenerse en sus condiciones para el Erario o los contribuyentes; proteger a los asentistas con la injusta idea de despojarlos siempre que se negasen a proseguir sus socorros y de arrebatar así de un solo golpe toda la fortuna pública reconcentrada en pocas

\footnotetext{
Campillo a Villarías, 14/01/1741. AHN, E, leg. 3149.

38 Existen similitudes entre una crítica anónima del manejo de Iturralde y Verdes Montenegro citada por Caro Baroja (op. cit. (nota 26), pp. 233-234) y la argumentación de Campillo: la denuncia de la inflación de juntas y, a continuación, de las tesorerías particulares; la justificación de la reunión de las tres Secretarías. Si el autor no es el propio Campillo, parece evidente que leyó sus cartas. La diferente formulación de los mismos argumentos muestra que se redactaron otros textos que las cartas a Villarías, tal vez para otro público. Además, la crítica anónima de las propuestas de Campillo redactada en 1742 confirma que las cartas redactadas entre enero y febrero de 1741 llegaron a manos de individuos que no eran precisamente amigos del futuro Ministro de Hacienda. Cfr. nota 33.
} 
manos; dar nuevos estímulos a las leyes penales del fisco, prescindiendo de sus relaciones morales; conmoverlo todo sin analizar ni reformar nada, estos fueron los atributos de una administración inquieta e ineficaz y estas las convulsiones que agitaron la monarquía, que apelaba vanamente a la mudanza de médicos cuando solo debía mudar de régimen." ${ }^{39}$

En el fondo, para Cabarrús, el rigor de Campillo para con los hombres de negocios se debía a que no conocía en profundidad los mecanismos de la economía y del crédito, aptitud indispensable para formar a un buen Ministro de Hacienda. Por eso, en 1786, lo opone a la figura de Ensenada.

Los historiadores contemporáneos, en línea con lo apuntado por el autor de origen francés, ponen el acento en el enfrentamiento de Campillo con los hombres de negocios, porque entra en coherencia con una política fiscal marcada por el inicio de la administración directa en ciertas provincias para las Rentas Provinciales y el esfuerzo por gravar más a los privilegiados. Desde este supuesto, la historiografía contemporánea observa una notable continuidad entre Campillo y Ensenada: Campillo abriría paso a una profunda reforma de la administración de la Hacienda, ampliada después por su sucesor, aunque se discute el alcance de su reforma de la fiscalidad, dada la brevedad de su ejercicio ${ }^{40}$. Sin embargo, interesa reparar en la ambivalencia de la estrategia referida por Cabarrús, quien no hablaba de un enfrentamiento franco con la gente de dinero sino de una combinación estratégica entre amenaza y protección. Pienso que la apreciación que en su día lanzase Cabarrús se corresponde con la realidad. En sus cartas y sus memorias de enero de 1741, Campillo no propone prescindir de los hombres de negocios - lo confirman sus propuestas para Italia- ni castigar a todos, sino seleccionar a los buenos y confiar esta elección al Ministro principal que él mismo aspira a ser. El programa es muy general y podrían haberlo asumido sus cuatro predecesores inmediatos. En sus dos años de ejercicio, hallamos algunos indicios que permiten precisar en qué medida se apartó de ellos.

\subsection{La afirmación del Ministro}

El esfuerzo por dejar el control de la actividad hacendística en manos del Ministro de Hacienda, más que en las del Tesorero General, evitando que otros gobernantes se entrometan en la distribución, me parece ser el rasgo más característico de la acción de Campillo. Sus nombramientos van en esta línea. El 27 de febrero de 1741, el rey le confía los empleos de Secretario del Despacho de Hacienda, Gobernador del Consejo de Hacienda y Superintendente de rentas generales, añadiéndoles "una absoluta inspección sobre toda materia de Hacienda y gastos de cualquiera especie que sean, suspendiendo todas las comisiones que se ejercen con separación e inhibición del Ministerio de Hacienda" ${ }^{41}$. Al poco tiempo, se extiende la autoridad de la

39 Cabarrús, F.: Elogio del Excelentísimo Señor Conde de Gausa, Madrid, 1786, Madrid, por la Viuda de Ibarra, Hijos y Compañía, pp. 13-16.

40 IbáÑez Molina, op. cit. (nota 16). Zafra Oteyza, op. cit. (nota 12), pp. 98-100 y 121-121. Andújar Castillo, op. cit. (nota 27).

41 Campillo a Prado Güemes, Buen Retiro, 27/02/1741. Archivo General de Simancas (AGS), Secretaría y Superintendencia de Hacienda (SSH), leg. 227-1. Felipe V al cardenal Molina, El Pardo, 27/02/1741. AHN, E, leg. 6401-1. Se precisan sus competencias de Superintendente de las rentas generales creadas en el marco de los servicios de millones a 05/03/1741. AHN, Fondo Contemporáneo (FC)-COGR, lib. 8014, fol. 246, núm. 690. 
Superintendencia al conjunto del ámbito fiscal-financiero, calificándose Campillo de "Superintendente General del cobro y distribución de la Real Hacienda"42. La calidad de Superintendente lo sitúa en la cúpula de una pirámide de intendentes, superintendentes, ministros, guardias y eventuales subdelegados invitados a cumplir sus órdenes. Asimismo, se le otorga la competencia dada ya a Patiño en 1727 de hacer transacciones para obtener el pago de los débitos a favor de la Real Hacienda sin que se mencione precedente alguno, tal vez por asumirse que esta prerrogativa ya forma parte del oficio de Ministro de Hacienda ${ }^{43}$. Por otra parte, en tanto Gobernador del Consejo de Hacienda, se le atribuye en abril de 1741 la supervisión de la cobranza del "diez por ciento" adoptado por la Junta de Hacienda a 22 de diciembre de 1740 , confiándole el conocimiento privativo "de esta materia con inhibición de todos los tribunales en primera instancia"44.

En cualquier caso, la reunión de los tres empleos de dirección de la Hacienda no es inédita -se beneficiaron de ella Campoflorido (a partir de 1721), Patiño, Verdes Montenegro e Iturralde. Sí resulta significativo el esfuerzo por explicarla, reiterándose la suspensión de las comisiones exteriores al Consejo de Hacienda y precisándose que Campillo también adquiere la condición de juez de valimientos. Asimismo, la referencia al carácter "absoluto" de la inhibición de los demás tribunales refleja la voluntad de prevenir cualquier tipo de recurso judicial o administrativo ${ }^{45}$. En junio de 1741, se amplía la esfera de competencias de la Secretaría de Hacienda a expensas del Consejo de Hacienda, situándose la Dirección de la Renta del Tabaco bajo la autoridad de la primera. De paso, esta vuelve a ser un órgano colegiado ${ }^{46}$. Campillo insiste una y otra vez en su voluntad de perseguir personalmente el fraude, aunque deba enfrentarse con grupos poderosos. Así, a 31 de enero de 1742, el rey deroga cualquier privilegio concedido a empleados en la percepción de rentas y a todos los que se valen de las inmunidades de los sitios reales, confiriendo a su Superintendente la facultad para perseguir el contrabando en estos lugares, incluso revisando $\operatorname{coches}^{47}$. Por otra parte, como comenta un crítico anónimo bien informado, Campillo se distingue de sus tres inmediatos predecesores obteniendo la facultad de despachar personalmente con el rey -mientras que ellos siempre pasaron por la vía del marqués de Villarías-, lo que le confiere una mayor influencia y autoridad en todo lo relativo al mundo de la hacienda ${ }^{48}$.

Puede que tan amplias competencias suscitaran la oposición de los tribunales, empezando por el Consejo de Hacienda. Así, en enero de 1742, el rey se ve obligado a reafirmar la facultad de Campillo de hacer transacciones en el cobro de algunos dé-

\footnotetext{
A 12/03/1741. AHN, FC-COGR, lib. 8014, fols. 245-249, núm. 690.

43 Felipe V a Campillo, El Pardo, 12/03/1741. AHN, FC-COGR, lib. 8014, fol. 246, núm. 690.

44 Felipe V al cardenal Molina, Aranjuez, 25/04/1741. AGS, SSH, leg. 399-1.

45 Felipe V a Campillo, El Pardo, 12/03/1741. AHN, FC-COGR, lib. 8014, fol. 246, núm. 690.

46 A 26/06/1741. Escobedo Romero, R.: El tabaco del rey. La organización de un monopolio fiscal durante el Antiguo Régimen, Pamplona, EUNSA, p. 42. GonzÁlez Enciso, A.: "Lenta recuperación y consolidación. La renta a mediados de siglo, 1740-1760" en GonzÁlez Enciso, A. (dir.): Política económica y gestión de la renta del tabaco en el siglo XVIII, Madrid, Los libros de Altadis, 2008, pp. 175-210.

47 AHN, FC-MH, libro 8014, núm. 727, fols. 414-415.

48 En las Secretarías de Marina e Indias, Guerra y Hacienda, puede despachar "por sí a los pies del rey, que le da toda la facilidad y autoridad que necesita para su mejor manejo, providenciando sin dependencia de nadie ni retardación cuanto puede convenirle al cumplimiento de sus encargos, siendo esta una ventaja que no lograron ni don Fernando Verdes Montenegro ni don Juan Bautista Iturralde ni el marqués de Torrenueva, y tan útil que por sí sola basta para autorizar al Ministro y vale por muchos millones en quien supiere servirse de ella". BNE, ms 12.641, fol. 210.
} 
bitos $^{49}$. Campillo entronca además con la política seguida por Campoflorido, Patiño o Iturralde, consistente en la afirmación de un espacio de gobierno propio de los ex$\operatorname{pertos}^{50}$. Así, en febrero de 1742, la reforma del Consejo de Hacienda eleva el número de consejeros de capa y espada, reduciendo el de togados al de la planta de 1720 y confiriendo voto a los tres Contadores Generales ${ }^{51}$. Por otra parte, las nuevas fuentes de financiación se incluyen en el área de competencias del Ministro. Es el caso del 10 por 100 "de la renta líquida que gocen los vasallos" ideado en 1740 y mantenido -con matices- a pesar de las críticas que le hiciera Campillo en enero de ese mismo año ${ }^{52}$. Asimismo, el Ministro dispone del uso de las mesadas anticipadas exigidas a los arrendadores de las Rentas Provinciales deseosos de prorrogar sus contratos y del recargo del derecho sobre la sal, que se puso en aplicación desde enero ${ }^{53}$. Cuando a fines de 1741, opta por la administración directa de las Rentas Provinciales en algunas provincias, esta se coloca a su vez bajo obediencia de su Superintendencia ${ }^{54}$.

En suma, Campillo cierra el paréntesis del experimento colegial de 1740, reafirmando la reunión de los tres empleos de Hacienda en una sola persona que ejerza la distribución de los fondos; pretende con ello acabar con las comisiones separadas, extendiendo su autoridad a todos los ramos de Hacienda; y por fin, se propone reducir el protagonismo de los tribunales y, dentro del Consejo de Hacienda, el protagonismo de los togados, dando mayor peso a los expertos.

Esta afirmación del poder del Ministro de Hacienda afecta también a los demás Secretarios del Despacho, al Ministro de Guerra y a los responsables del Almirantazgo de Marina, como lo anunciara en enero de 1741. Campillo busca conservar el monopolio de la distribución de fondos, reafirmando su papel institucional cuando Casimiro de Uztáriz, oficial mayor del Secretario de Guerra, parece querer infringirla. Su Majestad, apunta,

"tiene resuelto de que los efectos de la Real Hacienda se distribuyan por una sola mano y que esta sea la del Ministro destinado a este encargo" ${ }^{\prime 5}$.

La situación, sin embargo, no parece ser tan conflictiva como en el año anterior, dada la voluntad conciliadora de Uztáriz ${ }^{56}$. Campillo, naturalmente, se esfuerza por neutralizar cualquier intento de contestación a su dominio en la dirección de la Hacienda. En octubre de 1741, por ejemplo, aparta a Montemar ofreciéndole una salida honrosa - nombrado coronel de las Guardias Españolas, es enviado a Italia como general del ejército ${ }^{57}$, al cesarle en su oficio de Ministro de Guerra. Campillo asume la Secretaría de Marina e Indias, pasando su titular (José Quintana) a la Cámara de Indias. Por fin, aprovecha la partida del Almirante y su secretario, Ensenada, a

49 Gallardo Fernández, F: Origen, progreso y estado de las rentas de la corona de España, por (...), oficial de la Secretaría de Estado y del Despacho Universal de Hacienda, del Consejo de Su Majestad, su Secretario con ejercicio de decretos, Madrid, Imprenta Real, 1805-1808, t. I, p. 94.

50 Sobre esta: Dubet, op. cit. (nota 6).

51 Gallardo Fernández, op. cit. (nota 49), t. I, p. 95. AHN, E, libro 800.

52 Felipe V a Campillo, Aranjuez, 12/03/1741. AHN, E, libro 793.

53 Circulares de 17, 18 y 20/01/1741, Madrid. AHN, FC-COGR, lib. 8014, fols. 221-222, núm. 686. Gómez de Terán le confirma la disposición de los dos fondos mencionados a 26/05/1741. AGS, SSH, leg. 227-1.

54 Felipe V a Campillo, Buen Retiro, 22/11/1741. AHN, FC-COGR, lib. 8014, fol. 386, núm. 716.

55 Campillo a Uztáriz, Aranjuez, 04/05/1741. AGS, SSH, leg. 227-2.

56 A 11/05/1741, contesta que se observó la regla enunciada. AGS, SSH, leg. 227-2.

57 Glesener, op. cit. (nota 10). 
Italia, para hacerse con el control del Almirantazgo de Marina, antes de proceder a desmantelarlo ${ }^{58}$.

Este esfuerzo por monopolizar la dirección de la Hacienda permite entender por qué Campillo apenas retoca el diseño de la Tesorería General. En efecto, la planta publicada en abril de 1743 casi se limita a explicar elementos ya presentes en la de Patiño de octubre de 1726. Se insiste en particular en la necesidad de mantener una sola cuenta, la formada por el Tesorero General y los tesoreros de ejércitos, con el objeto de elaborar estados de fondos y cargas anuales que guíen al Ministro en la distribución de caudales. Se precisa, de forma más clara que antes, que el Ministro de Hacienda debe ser el único con competencias para emitir órdenes de pago ${ }^{59}$. Cabe advertir que, por otra parte, se amplía el espacio de competencias de la Tesorería, al devolvérsele los ingresos procedentes de la venta de oficios y mercedes de Indias, confiados el año anterior por Molina a un Tesorero particular, Miguel de Arizcun, a la sazón arrendador de lanas y asentista de víveres de Marina ${ }^{60}$. Dada la tutela del Ministro sobre la Tesorería General, la supresión de esta tesorería particular (abril de $1741^{61}$ ) extiende su campo de acción. Por fin, la planta de 1743 permite identificar los objetivos de este control del Ministro sobre la Tesorería General. Así, la planta de Patiño ya preveía cómo el Ministro de Hacienda debía velar sobre las habituales operaciones de transición entre un Tesorero General y su sucesor, dando su visto bueno a los impagos que el Tesorero saliente transmite al Tesorero entrante. La planta de Campillo explica por qué: se trata de prevenir los "considerables perjuicios que se han experimentado en la negociación de estos créditos y de los boletines que en su correspondencia se han dado por la Tesorería Mayor"62. La frase se refiere a los manejos que ya denunciaba Iturralde para justificar la suspensión de pagos de 1739 . Para Campillo, el remedio reside en la figura del Ministro, verdadero responsable de la política de crédito de la corona.

\subsection{Equilibrios entre casas de negocios}

¿Qué política financiera pretende aplicar Campillo, honrado con estas nuevas competencias de Ministro de Hacienda, Guerra, Marina e Indias? Conviene en este punto seguir al pie de la letra su proyecto de evitar los "perjuicios" procedidos de la "negociación" de los efectos del Tesorero General: no busca acabar con esta compraventa porque sabe que esta resulta inevitable, sino solo prevenir sus "perjuicios". Algunos elementos invitan a pensar que su proyecto, pragmático, solo intenta evitar que esta "negociación" escape a la vigilancia del Ministro, en definitiva el único a quien corresponde dictar sus condiciones.

58 En noviembre de 1741, se le designa como teniente del Almirante; en aquel entonces ya es el único miembro de la junta del Almirantazgo, cuyos miembros fueron apartados. A 11 de enero de 1743, suprime el empleo de Secretario del Almirantazgo. Pérez Fernández-Turégano, op. cit. (nota 29), pp. 469-470.

59 Sobre la planta de Patiño: Dubet, op. cit. (nota 4), parte III, cap. IV-4. Sobre la de Campillo: Dubet, A. y SolbeS FERri, S.: La Tesorería General y la construcción del Estado español en el siglo XVIII, en prensa..

60 Sucedió a su tío Norberto. Torres SÁncheZ, R.: "Los navarros en la provisión de víveres a la Armada española durante el siglo XVIII" en TORRES SÁnchez, R. (dir.): Volver a la "hora Navarra”. La contribución Navarra a la construcción de la monarquía española en el siglo XVIII, Pamplona, EUNSA, 2010, pp. 213-262.

61 Disposición de 17/04/1741. AGS, SSH, leg. 399-1.

62 "Planta y reglas que por punto general deben observarse en la Tesorería Mayor, sobre el ingreso y distribución de caudales". El Pardo, 19/03/1743. AHN, FC-MH, libro 8015, n 772. 
Un primer indicio de la posición de Campillo viene dado por la selección del Tesorero General. No es indiferente el que elija a José Gómez de Terán (marzo de $1741)^{63}$. Este fue sucesivamente Tesorero (1723-1738) y Director (1738-1739) de la Renta del Tabaco. Lo destituyó Iturralde en 1739 por considerarle corresponsable de los usos ilícitos del nuevo Tesorero de la Renta, Herce. Ahora bien, Gómez de Terán no viene solo. Emplea en la caja de la Tesorería General a tres antiguos oficiales de la Tesorería del tabaco, que trabajaron bajo la autoridad de Herce y probablemente de él ${ }^{64}$. No sorprende que Gómez de Terán opte por emplear a oficiales de confianza para la oficina más estratégica de la Tesorería, la caja principal, en la que se suelen recibir los diversos créditos que tanto inquietan a los responsables. Lo significativo es que Campillo también otorga su confianza a un grupo procedente de la Renta del Tabaco. Tal decisión significa, a lo menos, que no admite las acusaciones de que fueron objeto en 1739. El trato dado a Herce confirma su buena disposición hacia la antigua red urdida en torno a la Renta del Tabaco. Herce continúa reclamando el reembolso de sus haberes, como otros individuos afectados por la suspensión. En mayo de 1742, en su calidad de "agente general que fue de la Tesorería General", se esfuerza por explicar que cuando remitía letras de cambio a la caja principal, a los comerciantes con los que trataba les reconocía el interés de la letra a partir de la fecha del primer giro. El contador de ordenación de la cuenta del Tesorero General de aquella época, no obstante, se empeña en no admitir este uso comercial de las letras de cambio ${ }^{65}$. Campillo arbitra a favor de Herce, considerando aquí, como Gómez de Terán -el Tesorero actual-, que la Tesorería General puede convivir con los usos de los mercaderes.

No obstante, no se trata de aventajar a los adversarios de Iturralde para castigar a la "constelación Goyeneche". En efecto, al mismo tiempo, Campillo ofrece una protección interesada a la red del antiguo Ministro. Este, en octubre de 1725, hizo dos contratos conexos con el rey, en nombre de la compañía que formaba con Juan de Goyeneche y con el marqués de Valdeolmos. Uno de ellos era un préstamo a interés de 22 millones de reales, a cambio de que el rey cancelara una lista de créditos más o menos antiguos de Iturralde y sus socios (por un total de 9 millones) contra la Tesorería General. El otro contrato era la adquisición "en empeño a gozar y gozar" de la renta de población de Granada, por 15 millones de reales. En el verano de 1740, el cardenal Molina tomó la iniciativa de una persecución judicial contra Iturralde, formándose una junta ad hoc. En marzo de 1741, el fiscal del Consejo de Hacienda, Blas Jover Alcaraz, redacta la acusación formal, acusando en particular a Iturralde de haber hecho el préstamo al rey con créditos "intrincados", que no siempre correspondían a deudas del rey, una forma de acusarlo del tan odiado beneficio de efectos del Tesorero General; gracias a la fraudulenta operación, habría comprado la renta de Granada $^{66}$. Interesa la posición adoptada por Campillo. Se enfrenta a Molina, quien sigue la causa con interés y, en mayo, pide que se acelere el proceso, concentrándose

63 Campillo a Villarías, Buen Retiro, 28/02/1741. AGS, SSH, leg. 227-1. Decreto de nombramiento de Gómez de Terán, 02/03/1741. AGS, SSH, leg. 234-2.

${ }_{64}$ Campillo a Villarías, Buen Retiro, 04/03/1741. AHN, SSH, leg. 227-1. Vega a Iturralde, Madrid, 14/03/1739. AGS, SSH, leg. 409-2. Planta de 19/03/1743, loc. cit. (nota 59).

65 Memorial de Herce al rey, s.f., y orden de Campillo a Lobato, Aranjuez, 18/05/1742. AGS, SSH, leg. 228-1.

66 Sobre esta causa: Dubet, A.: "Entre servicio del rey y tráfico de efectos: la doble negociación de Juan Bautista de Iturralde", Librosdelacorte.es, n 13, Otoño-invierno 2016.

(https://revistas.uam.es/librosdelacorte/article/view/7041/7410) 
la acusación en los herederos directos de Iturralde, sin los copartícipes de la compra $^{67}$. Campillo responde con ironía y saña, sorprendiéndose de que el propio Gobernador de Castilla pretenda obviar el procedimiento judicial ordinario y sospechando que desea proteger a sus propios amigos (en efecto, Pinedo, protegido de Molina, adquirió una porción de la renta de Granada ${ }^{68}$. Esta no es su última acusación contra Molina: en agosto del mismo año, llegará a afirmar que Molina, desde la muerte de Patiño, siempre se dedicó a "azotar a los Ministros de Hacienda", prometiéndoles tesoros miríficos o atemorizándolos, dejando en mal estado todos los negocios en que se introdujo ${ }^{69}$. Entretanto, Campillo resuelve la situación de los herederos de Iturralde de forma contundente. Revoca la comisión de la junta encargada de perseguir a Iturralde, remitiéndola a la Sala de Justicia del Consejo de Hacienda y sus tres fiscales, una forma de tomar el control sobre ella. Al poco tiempo, aparta al fiscal Jover Alcaraz. En marzo de 1742, la Sala de Justicia, en la que entra Campillo como Gobernador, se pronuncia en Consejo pleno a favor de la licitud de las negociaciones de Iturralde. Se prohíbe en adelante cualquier recurso judicial contra ellos ( 27 de mayo de 1742). En seguida, la viuda de Iturralde ${ }^{70}$ ofrece un nuevo "voluntario servicio" de 3 millones en nombre de todos los "interesados y partícipes en la Renta de población del Reino de Granada". La cantidad se suma al precio inicial de 15 millones, confirmándose después del pago que la venta es "cierta y segura" " La operación es provechosa para las dos partes: el rey recibe tres millones en moneda efectiva, pagados en la caja de la Tesorería General, mientras los herederos de Iturralde y sus socios, además de la tranquilidad, obtienen la confirmación de la posesión de una renta que les dará frutos hasta 1760.

De este modo, Campillo incluye en los negocios de la Hacienda real a grupos de hombres de negocios que fueron rivales en 1739-1740, sacando de ellos los capitales que pueden dar e imponiéndose como el ministro responsable y el iniciador de la política a seguir. Esta política no siempre excluye el castigo o la amenaza. Su crítico anónimo reprocha así a Campillo la confirmación de la administración directa de las Rentas Generales (a expensas de Giraldeli, por tanto) y "la escandalosa rescisión" del arrendamiento de la renta de aguardientes, que ejercía Lorenzo Ferarri, objeto además de persecución judicial ${ }^{72}$; este autor considera además el trato con los interesados en la renta de Granada como una forma de extorsión ${ }^{73}$.

Aun así, el objetivo del Ministro parece ser el restablecimiento de la confianza en el mundo financiero, atenuando las consecuencias de la suspensión de 1739. En el verano de 1741, se reconoce sin ambages que se debe satisfacer un interés del 3\% a los interesados en algunas de las mayores operaciones incluidas en el decreto de suspensión. Es una forma de afirmar la legalidad de sus anticipaciones, distinguiéndolas de las operaciones culpables vituperadas en el decreto (en este caso los prestamistas debían cobrar su capital sin ningún interés). Entre los beneficiarios, está Giraldeli,

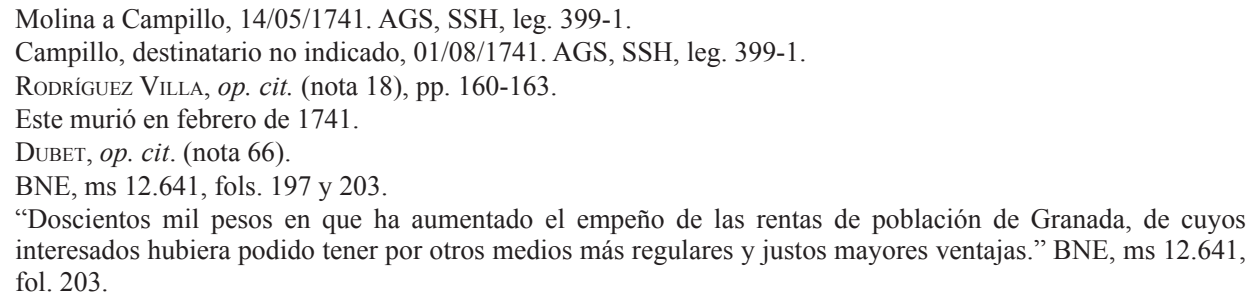
interesados hubiera podido tener por otros medios más regulares y justos mayores ventajas.” BNE, ms 12.641, fol. 203. 
quien solicita el reembolso de 3 millones prestados en dinero efectivo y en letras de cambio a partir de la mediación de Herce. Asimismo, se extiende el beneficio a todos los que, como él, participaron en unas anticipaciones de 4,5 millones realizadas por mano de $\mathrm{Herce}^{74}$.

Incluso Campillo parece querer ir más lejos. En efecto, Alejandro de Vega conserva una "Relación de las cantidades que se han librado por la Tesorería General del cargo del señor don Joseph Gómez de Terán desde 3 de noviembre de 1741 hasta fin de febrero de 1742 a diferentes hombres de negocios de esta corte por distintos créditos que Su Majestad mandó habilitar, procedidos de dinero efectivamente anticipado a la Real Hacienda para urgencias así sobre rentas arrendadas como sobre la caja de ella"75. Según Vega, los beneficiarios son "hombres de negocios y otras personas por créditos suspendidos y comprendidos en la orden general". La intención de Campillo no es pagarlos al contado, sino convencerles para esperar a los reembolsos, en muchos casos durante varios años: según la relación copiada por Vega, se les dieron cartas de pago sobre diversas rentas, con plazos más o menos distantes (hasta 1748 en algún caso). Giraldeli recibe así 11,28 millones de reales en " 28 mesadas que cumplen en agosto de 1743 y producto de las aduanas de Málaga y Sevilla (...) por créditos suspendidos, 7 millones de dinero efectivo y el resto de créditos contra el rey". Algunos reciben incluso "libramientos lisos y llanos" sobre la misma caja de la Tesorería General. Estos nuevos créditos distribuidos a los acreedores víctimas de la suspensión totalizan unos 41,07 millones de reales, una cantidad sustancial por lo tanto (el $41 \%$ de los efectos suspendidos por Iturralde), lo que indigna a Vega: "bien pudiera haberse evitado la extinción para dejar las rentas solventes" pues "con la mitad de ella quedarían locos de contento los recaudadores" $"$.

\subsection{Precios y premios}

La aparente benevolencia de Campillo con diversos grupos de hombres de negocios parece proceder de la conciencia de que resulta inevitable admitir sus ganancias, incluso cuando especulan con los efectos del Tesorero General. El Ministro, en consecuencia, no pretende suprimirlas, sino fijar el valor de los premios consentidos a los hombres de negocios, obteniendo contrapartidas jugosas para el rey.

El juicio de Campillo sobre el caso de Iturralde va en esta línea. Campillo explica en efecto que la sospecha de fraude de Blas Jover solo puede ser calificada de infundada. La renta no fue vendida sino empeñada, por lo que el precio pagado no pudo ser injusto. En cuanto a los medios de pago de Iturralde y sus amigos,

"quiero desde luego admitir que el señor marqués de Murillo pagó esta negociación y otras muchas con trapos viejos que llamamos, esto es, con créditos o alcances quizá mandados no pagar, comprados a 1 por 100, y no encuentro motivo alguno para poder proceder ni repetir contra el señor marqués ni sus representantes porque las negociaciones fueron hechas con la mayor solemnidad, tratadas, conferidas y acordadas con los Ministros de más autoridad que Vuestra Majestad

\footnotetext{
74 Memoriales de Giraldeli, antes de 12/09/1740. Opinión del contador Diego Rafael Anselmo, 25/11/1740. Decisión de Campillo, 27/08/1741. AGS, SSH, leg. 227-2.

75 AHN, E, 1. 831.

76 Ibidem.
} 
tuvo en aquel tiempo, los cuales, así como el señor marqués procuró mejorar su condición, debieron solicitar el beneficio de la Real Hacienda, como es de creer lo harían. Y cuando así no hubiese sido, podría resultar suficiente causa para degollar en un cadalso sus estatuas por haber mal usado de la confianza de Su Majestad, pero no culpa leve contra el señor marqués." 77

Los hombres de negocios compran con fuertes rebajas ( $¡$ al 1\% de su precio!) los créditos de la Tesorería General que se dejan de pagar e incluso los "mandados [por el rey] no pagar", para usarlos en sus liquidaciones a la Real Hacienda a un precio nominal. Parece natural que Iturralde "procur[e] mejorar su condición" a partir de esta dinámica. En tales condiciones, lo único punible podría ser la negligencia de los Consejeros que no lo advierten al preparar los contratos. Campillo no reflexiona aquí sobre la licitud del interés (en las operaciones de compra de viejas deudas por debajo de su precio), ni explica por qué es normal que un hombre de negocios busque enriquecerse. Sea por prudencia o por no perder tiempo, admite esta realidad. El corolario de su breve reflexión es probablemente que la ganancia de Iturralde y sus socios fue lícita porque la consintió el rey, tal vez como una forma de premio. A su vez, el nuevo servicio "voluntario" de la viuda de Iturralde es una contrapartida de la gracia real. Sin duda Campillo calculó que resultaría más fructífera para el rey la deuda moral impuesta a los socios de Iturralde que lo que se podía sacar de una deuda legal revelada por la persecución judicial.

La búsqueda de contrapartidas pasa a ser el criterio básico para asignar nuevos contratos de asiento y arrendamiento. En 1741, Campillo aprovecha la renegociación de los contratos de arrendamiento de Rentas Provinciales con sus titulares actuales para reducir de forma sustancial su tipo de interés. Es, sencillamente, lo que se puede deducir de un estado de fondos presentado por Gómez de Terán a 7 de mayo de 1741. Según este documento, el tipo de interés es del 4,03 por 100 en lugar del 8 por 100 en uso en la década anterior ${ }^{78}$. Se trata por tanto de una verdadera inflexión en la relación de la monarquía con sus arrendadores, aunque no se modifique el régimen de recaudación. Este logro es el resultado de un trabajo constante, confiado al Tesorero General, bajo la dirección atenta del Ministro: Gómez de Terán negoció desde abril para que los arrendadores actuales admitiesen en sus pliegos las propuestas de Campillo. Entre ellas, figura la concesión de una anticipación de 6 mesadas. En contrapartida, el Ministro está dispuesto a "extinguir" parte de los créditos de los arrendadores, eligiendo él mismo las mesadas en que se les vaya abonando ${ }^{79}$. Sin duda algunos de los compromisos que critica Vega derivan de aquí (convendría poderlos comparar con los de los predecesores de Campillo para evaluar la benevolencia del Ministro). No obstante, Campillo tampoco hace gala de una generosidad indiscriminada. La puesta en administración directa de las rentas de algunas provincias (Sevi1la, Toledo, Córdoba, La Mancha y Palencia), adoptada en octubre de 1741, da fe de ello. Como supone Miguel Artola, se trata probablemente de las rentas cuyos arren-

Campillo, destinatario no indicado, 01/08/1741. AGS, SSH, leg. 399-1. Iturralde fue premiado con el título de marqués de Murillo al dimitir.

78 El fondo desembarazado es de 4.766.223 reales para los gastos de fuera de la corte y 3.722 .714 para los que se hacen en ella. Los gastos de conducción estipulados con los hombres de negocios son de 150.000 reales. O sea, el 4,029 por 100 del dinero que se debe conducir a la corte. AGS, SSH, leg. 227-2.

79 Gómez de Terán a Campillo, Madrid, 08/04/1741, 18/04/1741, 26/05/1741. AGS, SSH, leg. 227-1. 
dadores no hicieron ofertas satisfactorias ${ }^{80}$. La estrategia adoptada en la provisión de Marina es similar: Campillo presiona para que el asentista reduzca sus exigencias de anticipaciones y exenciones fiscales. Acaba concediendo el asiento a una nueva casa de negocios, la de Ambrosio Agustín Garro (1742), lo que no significa la exclusión completa del titular anterior, el tan culpable Arizcun, a la sazón primo de Garro ${ }^{81}$.

Esta generosidad interesada tiene sus límites. Cabe suponer que los arrendadores de la renta del aguardiente y de las Rentas Generales no ofrecieron precios satisfactorios, por lo que no se renovan sus contratos -sería deseable encontrar las cartas intercambiadas entre ellos y el Ministro para averiguar sus razones. En lo concerniente al crédito, en el verano de 1742, Campillo afirma su determinación de dejar de pagar de forma indiscriminada los "créditos atrasados" heredados del siglo XVII. Considera en este punto que los que no fueron objeto de reclamaciones hasta el momento ya fueron compensados en su día: muchas casas ya recibieron el equivalente de 3 o 4 veces su capital inicial, gracias al "poco examen de las cuentas". En cuanto a los demás créditos, serán sometidos al examen de una junta ad hoc, pudiendo esperar, como máximo, el pago de un 3 por 100 de interés ${ }^{82}$. En definitiva, ciertas concesiones a los hombres de negocios superan cualquier límite, incluso para Campillo, aunque su grado de tolerancia hacia los agentes financieros sea mayor que el de Vega.

En esta política que combina la presión directa del Ministro de Hacienda sobre los hombres de negocios y el esfuerzo por restablecer el crédito de la Monarquía, las bases del crédito no cambian radicalmente. Como señala Agustín González Enciso al analizar la política de recaudación de rentas, Campillo no está convencido de la superioridad absoluta de la administración directa ${ }^{83}$. En este ámbito, se sitúa en la continuidad de la mayor parte de los gobernantes anteriores, en particular Patiño ${ }^{84}$, y de pensadores como Uztáriz o Vega, que estiman que se deben considerar las ventajas relativas de cada forma de recaudación en cada caso. Asimismo, Campillo comparte la convicción de algunos de sus predecesores ${ }^{85}$, de que entregar la recaudación de Rentas Provinciales a las justicias de los pueblos resulta tan dañoso como el propio arrendamiento ${ }^{86}$. Esto explica por qué las soluciones adoptadas son variadas. Se mantiene la administración directa de las Rentas Generales y de la del tabaco, pero el arrendamiento continúa siendo la solución predominante para las salinas, las siete rentillas y las Rentas Provinciales ${ }^{87}$. El crédito de la Tesorería General, por tanto, sigue descansando sobre arrendadores, aunque la "constelación Goyeneche" dejó de ser su único respaldo. Habrá que esperar un lustro más para que se modifique drásticamente esta organización.

80 Artola, M.: La Hacienda del Antiguo Régimen, Madrid, Alianza, 1982, pp. 258-260.

81 Torres SÁnchez, op. cit. (nota 60). Imízcoz y Guerrero Elecalde, op. cit. (nota 7).

82 Real resolución de 03/07/1742. Decreto de 07/07/1742. AGS, DGT, Inv. 39, leg. 2 y AHN, FC-MH, libro 8014, núm. 741, fol. 448. Este es el decreto que critica el anónimo citado, considerando que la referencia a un tráfico de viejos efectos de la Tesorería es un mal pretexto. BNE, ms 12.641, fols. 192, 204-205.

83 GonzÁlez Enciso, A.: "La supresión de los arrendamientos de impuestos en la España del siglo XVIII", Tiempos Modernos, $\mathrm{n}^{\circ}$ 30, 2015.

84 En 1722, Campillo le atribuía una neta preferencia por el arrendamiento. EscAmilla, I.: Los intereses malentendidos: el consulado de comerciantes de México y la monarquía española, 1700-1739, México, UNAM, 2011, pp. 175-177. Sobre el pragmatismo de Patiño al respecto: SolBes FerRi, S.: "Uniformidad fiscal versus territorios privilegiados en la España del siglo XVIII: los casos de Navarra y Canarias", Espacio, Tiempo y Forma, n 27, 2014, pp. 135-160.

85 Delgado Barrado, op. cit. (nota 8).

86 Artola, op. cit. (nota 80), p. 287.

87 Ibidem, pp. 287-291. GonZÁlez ENCISO, op. cit. (nota 83). 


\section{Conclusión}

El legado que Campillo dejó a su sucesor fue doble. Se instauró una nueva relación con los hombres de negocios, en la que tanto en materia de arrendamientos como de asientos, el Ministro se mostró determinado a imponer condiciones más favorables a los intereses de la monarquía, pero sin dejar de reconocerles los beneficios necesarios para entrar en los negocios de la corona ni de ofrecerles garantías razonables de reembolso. Para conducir esta política, afirmaba sin ambigüedad que el gobierno de la Hacienda debía conducirse por la vía reservada de un solo Ministro de Hacienda, excluyendo tanto a los tribunales y sus letrados como a los demás Secretarios del Despacho, y ampliando aquí el espacio conquistado por Campoflorido, Patiño o Iturralde. En este esquema, la Tesorería General le permitía acceder personalmente a la información sobre los usos que los hombres de negocios hacían de sus efectos y prevenir así los fraudes más descarados. Campillo consideró así a la Tesorería General como una útil máquina para generar el crédito indispensable a la financiación de la monarquía. La "unidad del manejo" del erario real en España pasaría a depender esencialmente del Ministro, y solo en segundo lugar del Tesorero General: la solución institucional elegida por Campillo -en particular la reunión en sus manos de varias Secretarías-, distinta de las propuestas por sus predecesores inmediatos, le permitió crear las condiciones para controlar el gasto militar sin oponerse a la voluntad del rey de mantener cierta autonomía los departamentos de Guerra y Marina, ya que el nuevo Ministro no se opuso a consignaciones particulares que se hubiesen de concertar en cada uno de los departamentos.

Para entender las implicaciones financieras y sociales de este cambio de rumbo, sería útil recopilar información sobre las formas de reembolso que se negociaban en los contratos de arrendamiento y asiento concertados durante el mandato de Campillo. Asimismo, al objeto de evaluar el alcance del cambio, sería preciso conocer los argumentos de los grupos que pudieron oponerse a la política de Campillo. De momento, debemos contentarnos con la crítica anónima citada en varias ocasiones, que repara en la violencia ejercida sobre la gente de negocios. Por su parte, Astraudi señala que su patrón recibió una amenaza de muerte en el caso de no cumplir con las promesas hechas para que se le confiara el ministerio, otro indicio de la conflictividad generada por la política de Campillo ${ }^{88}$. Esta reflexión es uno de los ingredientes del trabajo de construcción del mito del gran hombre. Las dos fuentes, en cambio, nos dicen poca cosa de la naturaleza de la oposición a Campillo -aunque sí se sabe que el crítico anónimo tiene simpatía por Torrenueva-, pero sí sugieren que su política afectó a importantes intereses sociales y políticos.

$88 \quad$ Astraudi, op. cit. (nota 18), pp.139-140. 